\title{
ENCONTRO DO PIBID DA UEL: INTERDISCIPLINARIDADE, REFLEXÕES E A FORMAÇÃO DOCENTE
}

\author{
Cristiane Marques Araújo (SEED-NRE/Londrina - PIBID/Letras Espanhol - UEL) \\ Andrea Magalhães (PIBID/Letras Espanhol - UEL) \\ Erika Moreno (PIBID/Letras Espanhol - UEL) \\ Prof. ${ }^{\mathrm{a}}$ Dra. Valdirene Zorzo-Veloso (Orientadora)
}

\section{RESUMO}

O PIBID (Programa Institucional de Bolsas de Iniciação à Docência) foi instituído pela CAPES visando contribuir com a formação inicial de docentes em nível superior, fomentar a capacitação continuada aos professores atuantes nas escolas estaduais e municipais, e, consequentemente, promover o desenvolvimento e a melhoria da Educação Básica Nacional. Desde o ano de 2011, a Universidade Estadual de Londrina realiza o Encontro do PIBID da UEL, evento reunindo estudantes e professores envolvidos no Programa e retrata significativo elo entre as diferentes áreas de licenciaturas e interdisciplinares denominados de subprojetos. Nesse evento são apresentadas experiências vividas por estudantes dos cursos de licenciatura e por professores da rede pública de ensino, com enfoque na integração multidisciplinar e na exposição das ações desenvolvidas ao longo do ano nas escolas em que atuam os bolsistas. A integração e a interdisciplinaridade surgem como elementos essenciais para o fortalecimento e aprimoramento do PIBID, visto que a partir da troca de experiências, positivas e negativas, nascem reflexões e ações que melhoram o desempenho profissional e acadêmico. O subprojeto Letras-Espanhol participa mostrando impactos positivos na atuação dos bolsistas, na articulação da universidade e ensino fundamental e sua responsabilidade social. O presente estudo dialoga com LEFFA(2001), BRASIL(2011) e ZORZO-VELOSO(2013).

Palavras-chave: PIBID, formação docente, espanhol como língua estrangeira.

\section{INTRODUÇÃO}

O objetivo deste trabalho é apresentar a fundamental importância do Encontro PIBID da UEL, realizado desde 2011, que tem como finalidade incentivar a formação docente e promover o reconhecimento da licenciatura, no qual os integrantes do evento apresentam resultados e promovem a troca de experiências entre os participantes do projeto financiado pela CAPES (Coordenação de Aperfeiçoamento de Pessoal de Nível Superior) do Ministério da Educação (MEC), com enfoque na integração e na exposição das ações desenvolvidas ao longo de cada ano nas escolas em que atuam os bolsistas de iniciação à docência.

De acordo com Leffa (2001, p.110) "o grande desafio de se falar sobre ensino e aprendizagem é que não se pode falar sobre o momento atual: ninguém está interessado no que está acontecendo agora; queremos saber o que vai acontecer amanhã". Nunca houve tanta necessidade de se prever o futuro como agora, e o futuro nunca foi tão imprevisível. Este é um dos tantos desafios que a vida nos oferece: quanto mais 


\section{SEMINÁRIO DE PESQUISA EM CIÊNCIAS HUMANAS - SEPECH \\ Humanidades, Estado e desafios didático-científicos \\ Londrina, 27 a 29 de julho de 2016}

imprevisível for alguma coisa, maior será a necessidade de prevê-la. "O século $\mathrm{XX}$ descobriu a perda do futuro, ou seja, sua imprevisibilidade" (Morin, 2000, p. 75, apud LEFFA, 2001, p.110).

É indiscutível que no campo da Educação nasce uma nova situação: a interdisciplinaridade, que se mostra como fortalecimento do PIBID a partir da troca de experiências entre as diferentes áreas, incluindo um subprojeto Interdisciplinar. Segundo Fazenda (apud SILVA 2013):

"a interdisciplinaridade caracteriza-se por ser uma atitude de busca, de inclusão, de acordo e de sintonia diante do conhecimento. Logo, tornase explícito a ocorrência de uma globalização do conhecimento, onde, há o fim dos limites entre as disciplinas".

O trabalho interdisciplinar garante maior interação e união entre os alunos, e estes com professores, sem falar na experiência e no convívio em sociedade. Essa interdisciplinaridade surge como fortalecimento do Programa, com uma maior globalização entre as disciplinas, quebra de barreiras e o estreitamento de relações.

Como o PIBIB é estruturado em subprojetos, entre eles temos o subprojeto Letras-Espanhol, do qual formamos parte com atividades diretas nas escolas conveniadas, produção de materiais didáticos e formação inicial e continuada aos professores.

\section{O QUE É O PROGRAMA INSTITUCIONAL DE BOLSAS DE INICIAÇÃO À DOCẾNCIA (PIBID)}

O PIBID é um programa de bolsas de iniciação à docência com, no mínimo, três grandes agentes envolvidos e que possibilita que alunos dos cursos de licenciatura, bolsistas de iniciação à docência, comprometidos com o desenvolvimento da educação nas escolas públicas, vivenciem, ainda, na graduação, etapa da formação inicial, o dia-adia do contexto escolar.

O Programa também tem como proposta o incentivo à formação acadêmica continuada dos professores da Educação Básica, fazendo com que graduandos dos cursos de licenciatura acompanhem os professores em sala de aula, ajudando na elaboração e aplicação de atividades, colaborando com o desenvolvimento de projetos, discutindo dificuldades e propondo inovações - atividades desenvolvidas na escola. Além disso, instiga a produção de materiais didáticos diversos, realização de pesquisas em ensino e formação de docentes, encontros semanais para discussão e preparação de conteúdos para a sala de aula, participação em eventos nacionais e internacionais. De outro norte, a formação continuada desses professores que atuam na Educação Básica ganha um novo ânimo, com o Plano Nacional de Formação de Professores da Educação Básica - PARFOR. O PARFOR serve ao fomento da oferta de educação superior para os professores em atividade na rede pública de ensino, é o caminho para a concretização da formação específica para o magistério, na forma prevista na Lei de Diretrizes e Bases da Educação Nacional. 


\section{SEMINÁRIO DE PESQUISA EM CIÊNCIAS HUMANAS - SEPECH \\ Humanidades, Estado e desafios didático-científicos \\ Londrina, 27 a 29 de julho de 2016}

O outro pilar do PIBID são os impactos nos graduandos auxiliando-os a vivenciar a teoria e a prática, identificar os diferentes contextos escolares, aprender a importância do comprometimento ético na interação escola e comunidade.

Para completar a tríade do PIBID os impactos positivos na escola são visíveis. Outros professores (re)conhecem os benefícios por meio de alunos interessados, participativos e motivados com aulas diferenciadas e materiais atrativos. São ainda, instigados a refletir sobre seus procedimentos e incentivados a buscar novas capacitações.

\section{ESCOLAS ENVOLVIDAS, ALUNOS DA EDUCAÇÃO BÁSICA}

Nesse contexto, vários subprojetos são desenvolvidos na Universidade Estadual de Londrina, em parceria com escolas da rede pública e com seus professores que atuam como co-formadores, possibilitando que os futuros docentes, em formação inicial, tenham uma atuação no contexto para que esta formação seja aprimorada. $\mathrm{O}$ que se visualiza é uma intensa troca de experiências e percepções do meio escolar, possibilitando que os futuros docentes, em formação inicial, tenham uma atuação decisiva para que esta formação seja aprimorada.

Conforme dados extraídos da página eletrônica da Universidade Estadual de Londrinaf $^{1}$, o PIBID, que começou em 2009 com 06 subprojetos, evoluiu ao longo dos anos e conta atualmente com 16 subprojetos, um Interdisciplinar (Biologia, Geografia, Música e Pedagogia) e mais 15 que envolvem todas as licenciaturas da UEL, nas seguintes áreas: Artes Visuais, Ciências Biológicas, Ciências Sociais, Educação Física, Filosofia, Física, Geografia, História, Letras- Espanhol, Letras-Inglês, Letras Português, Matemática, Música, Pedagogia e Química.

Ainda de acordo com os dados constantes na página eletrônica da UEL, atualmente são desenvolvidas as seguintes atividades no PIBID/UEL:a) atividades que servem à complementação da formação acadêmica dos bolsistas e supervisores; b) atividades extraclasses, tais como grupos de estudos, oficinas, palestras, jornadas, aulas de reforço, minicursos e outros eventos; c) produção de materiais didáticos, jogos, pôster, textos, livros; d) atividades de pesquisa em ensino e formação de professores, são 15 mestrados e doutorados em andamento; e) realização e participação em eventos em todo território nacional, publicações eletrônicas, etc.

\section{ENCONTRO DO PIBID DA UEL}

Em novembro de 2011 foi realizado o primeiro Encontro do PIBID da UEL, objetivando a reunião, em um único dia, de estudantes, professores da graduação e professores do ensino fundamental e médio envolvidos com o projeto.

Tais encontros anuais buscam a troca de ideias, de experiências, tanto dos professores que atuam como formadores e co-formadores, como dos alunos das licenciaturas. $\mathrm{O}$ evento também é aberto à comunidade possibilitando que a comunidade

\footnotetext{
${ }^{1}$ www.uel.br
} 


\section{SEMINÁRIO DE PESQUISA EM CIÊNCIAS HUMANAS - SEPECH \\ Humanidades, Estado e desafios didático-científicos \\ Londrina, 27 a 29 de julho de 2016}

escolar e acadêmica, como demais interessados, enfim, todos possam participar como ouvintes.

A organização do evento pode oscilar a cada edição, mas a estrutura básica tem sido a exposição de banners criados por cada grupo, subprojetos, que atuam nas diferentes escolas; comunicação oral mostrando as ações e os programas desenvolvidos com os alunos. Nesse primeiro momento, então, todos têm um contato inicial com a dinâmica do PIBID em cada colégio e como as diferentes licenciaturas encaminham suas ações.

$\mathrm{Na}$ segunda parte do Encontro do PIBID da UEL são formados grupos de trabalho, que reúnem graduandos e professores de diversas licenciaturas. A partir dessa divisão se intensifica o diálogo, possibilitando o contato direto, por exemplo, de graduandos em Física com graduandos em Ciências Biológicas e Letras-Espanhol para esse intercambio de experiências e vivências.

Cada grupo envolvido com um subprojeto, lembrando que cada licenciatura forma um subprojeto, relata sua experiência na escola, inclusive com ponderações sobre as expectativas e aquilo que foi efetivamente alcançado, bem como sobre as melhorias que foram sendo, pouco a pouco, implementadas. É importante ressaltar que cada participante dos subprojetos tem a possibilidade de falar com uma plateia diversificada, com destinatários que conhecem contexto educacional diversificados, o que possibilita a construção de um discurso mais detalhado das ações realizadas e, assim, uma reflexão da sua práxis.

A partir desses encontros e dessa diversidade de pensamentos, de realidades e de interesses, nasce à interdisciplinaridade, elemento que tem se mostrado fundamental para formação humana e, em especial, para a formação docente, inicial e continuada.

\section{INTERDISCIPLINARIDADE E FORMAÇÃO DOCENTE}

O que seria do indivíduo se vivesse no completo isolamento? O que seriam das ideias se estivesse presas a uma caixa inviolável? O que seria do mundo sem interação e diversidade? Ou, melhor ainda, sem interação entre o que é diverso?

Todos estes questionamentos trazem à tona a ideia da interdisciplinaridade, ou seja, da interação entre disciplinas diversas. No contexto educacional, a interdisciplinaridade começou a ser abordada a partir da Lei $n^{\circ} 5.692 / 1971$, Lei de Diretrizes e Bases para o ensino de $1^{\circ}$ e $2^{\circ}$ graus. Desde então, tem-se desenvolvido um trabalho que busca a integração entre os diversos campos do conhecimento, com a complementação e a combinação de atividades, interesses, metodologias e práticas.

Podemos estabelecer que a origem da interdisciplinaridade esteja nas mudanças de percepções que temos da vida, já que à medida que as relações humanas se tornam mais complexas, maior é a importância que damos aos elos de entendimento nos variados campos do conhecimento.

O espírito crítico também fortalece a interdisciplinaridade, visto que quando educando e educadores refletem e tentam compreender melhor o processo ensino e aprendizagem cria-se uma visão de totalidade, onde os diversos campos do conhecimento dialogam e se complementam. 


\section{SEMINÁRIO DE PESQUISA EM CIÊNCIAS HUMANAS - SEPECH \\ Humanidades, Estado e desafios didático-científicos \\ Londrina, 27 a 29 de julho de 2016}

Os encontros do PIBID da UEL não deixam margem à dúvida, certamente é muito valioso unir pessoas, com diferentes formações e, aparentemente, com conteúdos de aprendizagem muito diversificados, em torno de um objetivo único, que é o aprimoramento da formação docente.

O que se vislumbra é a possibilidade do trabalho em equipe, tanto entre aqueles que ainda estão sendo formados, os futuros professores, como entre aqueles que já exercem suas atividades nas escolas do ensino público. A partir das experiências relatadas por cada grupo/subprojeto os horizontes são ampliados, com a visualização da interdisciplinaridade como fator chave para a concretização de uma formação global, onde o diálogo tem papel decisivo.

Num momento em que se discute a crise no sistema educacional público, a busca por soluções inovadoras nunca se fez tão necessária, sendo que é justamente para afastar o caos que surge a ideia de um conhecimento criado, numa primeira impressão, de forma caótica. Ocorre que a junção de diferentes áreas do pensamento humano para a construção do conhecimento pode se revelar organizada e eficaz.

Certamente é um processo de ensino e aprendizagem que requer a adoção de métodos, os quais estão em constante processo de aprimoramento. Neste ponto, a troca de experiência nos encontros do PIBID é de grande valia, inclusive porque os interesses dos alunos do ensino fundamental e médio também são revelados pelos bolsistas, que no contato diário percebem quais atividades ou conteúdos foram encarados com mais disponibilidade e satisfação. Desenvolver o ensino interdisciplinar a partir de pontos que são mais interessantes aos olhos dos alunos poderá abrir passagem para conteúdos mais complexos ou, simplesmente, tidos como pouco importantes pelos estudantes.

A ideia da interdisciplinaridade não é exatamente nova, nascida na década de 60 na França e Itália, influenciou as reformas do cenário educacional brasileiro trazida desde a edição da Lei de Diretrizes e Bases do ano de 1971, Lei no 5.692/71. De igual modo, os Parâmetros Curriculares Nacionais também apresentam a interdisciplinaridade como proposta para uma educação contemporânea, conectada com a realidade atual. Contudo, ainda existem muitas barreiras que impedem seu avanço como norteador do sistema de ensino.

A reflexão que se propõe, assim, a partir do que é verificado na prática com os encontros do PIBID/UEL, diz respeito à riqueza da interdisciplinaridade, aplicada dentro e fora da sala de aula.

$\mathrm{Na}$ formação docente, o contato entre as diversas áreas do conhecimento e as informações sobre os projetos trilhados ao longo do ano, possibilitam que os graduandos pensem em como os mesmos projetos e atividades poderiam ser aplicados na sua área específica de atuação.

Por outro lado, o encontro entre os professores e futuros professores de diferentes áreas faz com que os olhares se voltem para as tantas possibilidades de construção de um conhecimento que dialoga que é formado a partir da junção de diferentes disciplinas. A fragmentação do conhecimento dá espaço para o pensamento que busca a compreensão do todo, em que o entendimento entre os diferentes profissionais da educação tem como foco o aprimoramento do ensino, a eficácia na formação do aluno, como estudante e futuro cidadão. 


\section{SEMINÁRIO DE PESQUISA EM CIÊNCIAS HUMANAS - SEPECH \\ Humanidades, Estado e desafios didático-científicos \\ Londrina, 27 a 29 de julho de 2016}

\section{CONSIDERAÇÕES FINAIS}

É indiscutível que, o Encontro do PIBID da UEL, resgata e conquista bons resultados no que implica o desenvolvimento de estratégias de ensino e aprendizagem, postura pedagógica e busca de novos rumos metodológicos. Estamos vivendo em uma era rápida de informações, anseios e de adaptação de mercado tornando um assunto capacitação relevante e de constante evidência. A formação continuada vem fazer exatamente essa ponte necessária para se atualizar sempre mais. Com essa (re) alimentação de práticas e teorias e a partir das reflexões e aproximações teóricas e didáticas, do respeito, da integração professor-professor-aluno, da interdisciplinaridade, do comprometimento mútuo confiamos nas melhorias e sucesso do exercício educacional na rede pública- fatores chaves ao formar um profissionais.

Ressaltamos e destacamos ainda que o evento corrobora no que diz ZorzoVeloso (2013, p.34) que a formação de professores e as suas múltiplas e distintas dificuldades encontradas ao conduzir uma aula é tarefa e de total responsabilidade da Universidade cumprir o seu papel como instituição pública formadora de educadores. $\mathrm{E}$ que os relatos de experiências e de práticas de ensino apresentadas no evento, sem dúvida alguma, auxiliam na formação de um profissional crítico e comprometido com o seu exercício educacional.

Para concluir, a importância da formação inicial e continuada para a carreira profissional deve ser vista como estratégia que melhora suas diversas competências, habilidades e conhecimentos, a fim de atualizar e acompanhar essa era volátil em que vivemos.

\section{REFERENCIAS}

BRASIL. Lei $\mathrm{n}^{\circ}$ 5.692, de 11 de agosto de 1971. Fixa Diretrizes e Bases para o ensino de $1^{\circ}$ e $2^{\circ}$ graus, e dá outras providências. Diário Oficial da União, 12/08/1971.

LEFFA, V. J. O ensino de línguas estrangeiras nas comunidades virtuais. In: IV SEMINÁRIO DE LÍNGUAS ESTRANGEIRAS, 2001, Goiânia. Anais do IV Seminário de Línguas Estrangeiras. Goiânia: UFG, 2002. v. 1, p. 95-108. Disponível em: <http://www.leffa.pro.br/textos/trabalhos/comunidades.pdf $>$. Acesso em 27 mar 2016.

Parâmetros Curriculares Nacionais. Disponível em: $<$ http://portal.mec.gov.br/seb/arquivos/pdf/livro081.pdf>. Acesso em 19 abr. 2016. SILVA, Renata Ferreira da Silva. Importância da interdisciplinaridade no processo de aprendizagem. Portal Educação: conhecimento para mudar sua vida, 2013. Disponível em $<$ http://www.portaleducacao.com.br/pedagogia/artigos/49573/importancia-dainterdisciplinaridade-no-processo-de-aprendizagem\#ixzz4ACSaRLBg $>$ Acesso em 28 mar 2016. 


\section{SEMINÁRIO DE PESQUISA EM CIÊNCIAS HUMANAS - SEPECH \\ Humanidades, Estado e desafios didático-científicos \\ Londrina, 27 a 29 de julho de 2016}

Universidade Estadual de Londrina. Disponível em:

$<$ http://www.uel.br/prograd/?content=pibid/pibid_uel.html>. Acesso em 19 abr. 2016.

ZORZO-VELOSO, Valdirene F. Ensinar español después de agosto de 2005: desafíos y perspectivas. In:Zorzo-Veloso, Valdirene F (org.). El español en línea de mira: enlaces lingüísticos, literarios y metodológicos. Londrina: UEL,2013. p.34 